\title{
Ebola response missions: To go or not to go? Cross- sectional study on the motivation of European public health experts, December 2014
}

U Rexroth (rexrothu@rki.de) ${ }^{1,2}, M_{\text {Diercke }}^{1,2}$, E Peron $^{1,3}$, C Winter $^{1}$, M an der Heiden ${ }^{1}$, A Gilsdorf ${ }^{1}$

1. Robert Koch Institute, Department for Infectious Disease Epidemiology, Surveillance Unit, Berlin, Germany

2. These authors contributed equally to this work

3. European Programme for Intervention Epidemiology Training (EPIET), European Centre for Disease Prevention and Control $(E C D C)$, Stockholm, Sweden

Citation style for this article:

Rexroth U, Diercke M, Peron E, Winter C, an der Heiden M, Gilsdorf A. Ebola response missions: To go or not to go? Cross-sectional study on the motivation of European public health experts, December 2014. Euro Surveill. 2015;20(12):pii=21070. Available online: http://www.eurosurveillance.org/ViewArticle. aspx?Articleld $=21070$

Article submitted on 11 March 2015 / published on 26 March 2015

We surveyed European infectious disease epidemiologists and microbiologists about their decisions to apply for Ebola response missions. Of 368 respondents, 49 (15\%) had applied. Applicants did not differ from non-applicants in terms of age, sex or profession but had more training in field epidemiology and more international experience. Common concerns included lack of support from families and employers. Clearer terms of reference and support from employers could motivate application and support outbreak response in West Africa.

\section{Background}

In 2014-15, Guinea, Liberia and Sierra Leone suffered from the largest ever recorded Ebola virus disease (EVD) outbreak [1]. In any response to infectious disease outbreaks, epidemiologists and microbiologists are crucial: they trace contacts, analyse epidemiological data and support laboratory testing $[2,3]$. The World Health Organizations' (WHO) Global Outbreak Alert and Response Network (GOARN), Médecins Sans Frontières (MSF), the United Nations (UN) and other organisations have been involved in the outbreak response and recruited experts for field missions to West Africa, but the lack of or limited number of volunteers restricted scaling up efforts [4].

Within the last 20 years, the European Union (EU)/ European Economic Area (EEA) countries and - since its foundation in 2005 - the European Centre for Disease Prevention and Control (ECDC) have trained ca 400 epidemiologists and microbiologists in outbreak response through the European Programme for Intervention Epidemiology Training (EPIET), the European Programme for Public Health Microbiology Training (EUPHEM) and associated Field Epidemiology Training Programmes (FETP -e.g. in Germany, Norway, the United Kingdom). The EPIET Alumni Network (EAN) incorporates alumni from these FETPs $[5,6]$.
Between 19 November and 7 December 2014, we surveyed European public health professionals in order to identify motivations and obstacles regarding their involvement in the local response to the Ebola outbreak. The knowledge gained from our study might help deploying organisations to adapt their recruitment strategies and thus strengthen the international response to large-scale outbreaks and other international public health emergencies.

\section{Data collection and analysis}

We collected information regarding applications for Ebola response missions, personal and professional background, and views on statements concerning qualification, motivation, fears and concerns related to those missions using a specifically developed online questionnaire.

The questionnaire included 85 questions. It was piloted among experts during the European Scientific Conference on Applied Infectious Disease Epidemiology (ESCAIDE, 5-7 November 2014) and programmed in LimeSurvey software, hosted on a server located in the Netherlands [7].

We recruited participants via respondent-driven sampling. First, we sent the online questionnaire to current EAN-members and other members of European public health institutes using informal networks. Second, we invited respondents to further distribute the link to the questionnaire into their professional networks.

We only analysed filled-in questionnaires of participants who had given informed consent. The data protection officer at the Robert Koch Institute approved this anonymous study.

In the analysis, we compared respondents who applied with those who did not apply for Ebola field missions in terms of various characteristics. Additionally, for 
each statement we compared agreeing and disagreeing respondents by frequency of applications to Ebola field missions, in order to measure the impact of the statement on the motivation to apply for missions. We calculated prevalence ratios (PR), 95\% confidence intervals (95\% CI) and $\mathrm{p}$ values (chi-square test and t-test) in STATA/SE 12.0 and considered a point estimate $p \leq 0.05$ as statistically significant.

\section{Characteristics of respondents}

A total of 368 respondents gave informed consent. Their median age was 38 years (range 21-66 years) and $69 \%$ were female. Fifty-one percent (173/342) had children; the median age of the youngest child was 5 years (range $0-37$ years). Respondents resided in 32 different countries; 25 of these countries were part of the European Union (represented by $95 \% ; 321 / 337$ respondents); respondents from other countries such as Barbados, Mozambique, Norway, Switzerland, Turkey and the United States were also included.

Of all respondents, 249 (68\%) were epidemiologists, $43(12 \%)$ were microbiologists and 98 (27\%) specified other professional backgrounds, including statistics, anthropology, biology, and veterinary medicine. Fiftytwo percent (138/264) were medical doctors (multiple answers were possible). The median professional experience was six years (range 0-35 years). Most respondents worked in the public sector (97\%; 316/327), had a permanent position $(64 \% ; 211 / 330)$, and had completed (or were currently enrolled in) an FETP (58\%; 189/327). Forty-six percent (151/330) were involved in Ebola-related activities at the time of the survey. Twenty-eight percent (93/329) mentioned previous experience in international outbreak response, partly in sub-Saharan Africa $(n=52)$ or other developing countries $(n=21)$.

Fifteen percent (49/329) had applied for recent Ebola missions to West Africa. Deploying organisations included WHO $(n=34), \operatorname{MSF}(n=14)$ and others $(n=16)$. Eighteen of the 49 applicants had already completed a mission, including 13 deployed by WHO and two deployed by MSF (average duration of missions 28 days; range 4-60 days).

The vast majority of respondents was fluent in English (89\%; 290/327), generally interested in missions (80\%; 249/312) and felt physically and psychologically fit (81\%; 248/308 and $74 \% ; 229 / 310$, respectively; Figure 1). Less than half considered themselves to be fluent in French $(41 \% ; 132 / 323)$.

\section{Respondents' views and attitudes on Ebola missions}

Seventy five percent of respondents thought they could be of help (245/328), 63\% considered themselves qualified (205/328), 67\% felt they were sufficiently trained about Ebola (217/325) and $71 \%$ had sufficient knowledge about self-protection from Ebola virus infection (229/322). Answers were more diverse concerning having the required vaccinations $(52 \% ; 160 / 308)$ and support of their supervisors $(46 \% ; 146 / 314)$. A minority had previous socio-cultural experience in the affected region $(31 \% ; 100 / 323)$ or time to go $(27 \% ; 82 / 305)$. Only 82 of 300 respondents (27\%) had been asked directly to join one of the missions.

\section{Factors increasing the motivation to apply for missions}

Many respondents pointed to elements that would increase their motivation to apply, including a clear job description (88\%; 248/283), meaningful tasks $(84 \% ; 233 / 277)$, guaranteed medical evacuation (83\%; $232 / 281$ ), a better match with own skills ( $82 \%$; 230/279) and better preparation (78\%; 220/281). Additionally, encouragement by the employer $(74 \% ; 205 / 276)$, personal recommendation by colleagues ( $59 \% ; 157 / 266)$, or confidence that someone else would take care of their routine work $(61 \% ; 163 / 267)$ could motivate many experts. The prospects to conduct research studies (35\%; 96/271), write publications (32\%; 86/272) and better payment $(33 \%$; 90/272) were less important in motivating applications (Figure 2).

\section{Factors that may hinder applications}

Most respondents stated that their families were concerned about their well-being $(87 \% ; 265 / 303)$, or that their families did not want them to go $(62 \% ; 187 / 302)$. Sixty-two percent (196/315) agreed that they were essential at their current job. Fewer considered other issues more important than Ebola $(27 \% ; 77 / 283)$ or regarded missions as too long $(24 \% ; 70 / 290)$, or not well enough paid $(12 \% ; 34 / 281)$. The need to use personal protective equipment (PPE) (16\%; 47/297), possibility of quarantine $(17 \% ; 49 / 293)$ or stigmatisation after return ( $11 \% 33 / 309)$ did not seem to be a major concern.

\section{Comparison between applicants and non- applicants to Ebola response missions}

Applicants differed from non-applicants neither in terms of age, sex, professional background, years of experience, nor in the age of their youngest child. However, they less often considered a mission to West Africa as very dangerous (11\%; $5 / 44$ vs $43 \%$; $103 / 239$; $\mathrm{p}<0.001)$ and less often worried about an Ebola infection (23\%; 10/44 vs 52\%; 126/244; p<0.001).

Applicants were more often trained in an FETP (76\%; $37 / 49$ vs $54 \% ; 145 / 268, p=0.005)$ and experienced in international outbreak response missions (59\%; 29/49 vs $23 \% ; 62 / 273 ; p<0.001)$, especially in sub-Saharan Africa (46\%; 22/48 vs 10\% 28/270; p<0.001).

Applicants were significantly more often directly asked to join an outbreak response mission (58\%; 22/38 vs $23 \%$; $58 / 250 ; p<0.001)$, had the time to go $(59 \%$; $22 / 37$ vs $24 \%$; 58/238; p<0.001), had previous sociocultural experience in West Africa (59\%; $27 / 46$ vs $26 \%$; $69 / 268 ; p<0.001)$, and had the required vaccinations 


\section{FIGURE 1}

Statements concerning Ebola response mission by level of agreement of European public health professionals, December 2014

I am essential in my current job

After reading the TORs, I feel that I can assess the personal risks

I have the required vaccinations

I am indispensable for my family

My boss would release me from my tasks

I am worried about getting infected with Ebola

I am fluent in French

I am worried about getting infected with other diseases

I consider a mission to West Africa as very dangerous at the moment

I fear that I might end up doing other things than I prepared for

I have socio-cultural experience in Western African countries

Medical evacuation is not guaranteed

I am worried I could infect others after my return

I was asked to join field mission in the current Ebola-outbreak

I consider other things more important than Ebola

I think that preparations (trainings) for such a mission are not sufficient

I have the time to go

The risks are not covered well by the sending organisation

Missions are too long

I am worried that I cannot leave the country

I am worried of being put under quarantine after my return

I am discouraged by the need to use personal protective equipment

I think it is not well enough paid

I fear possible stigmatization after my return

I fear my family will be stigmatised after my return
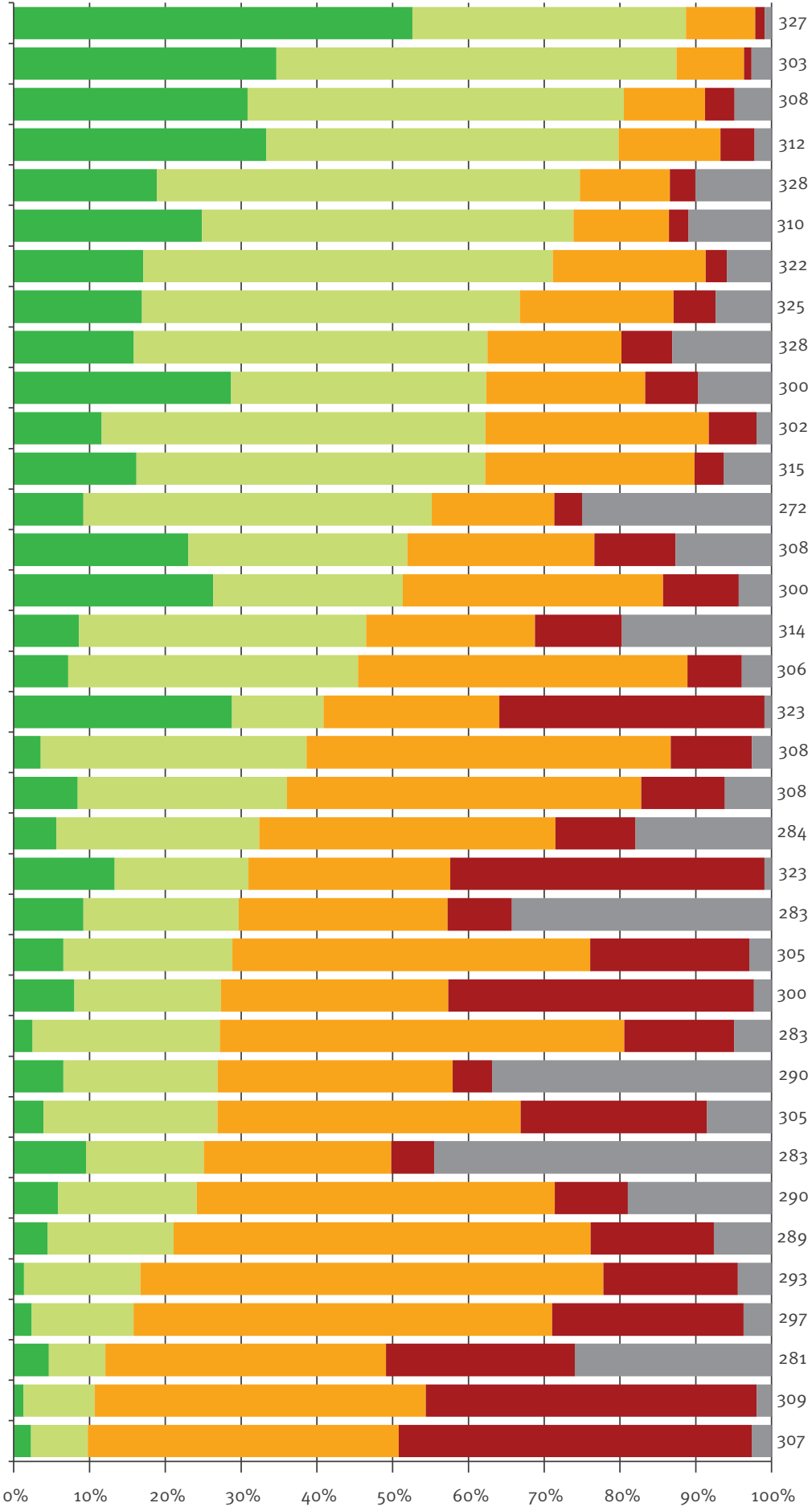

Percent of answers

TOR: Terms of reference. 


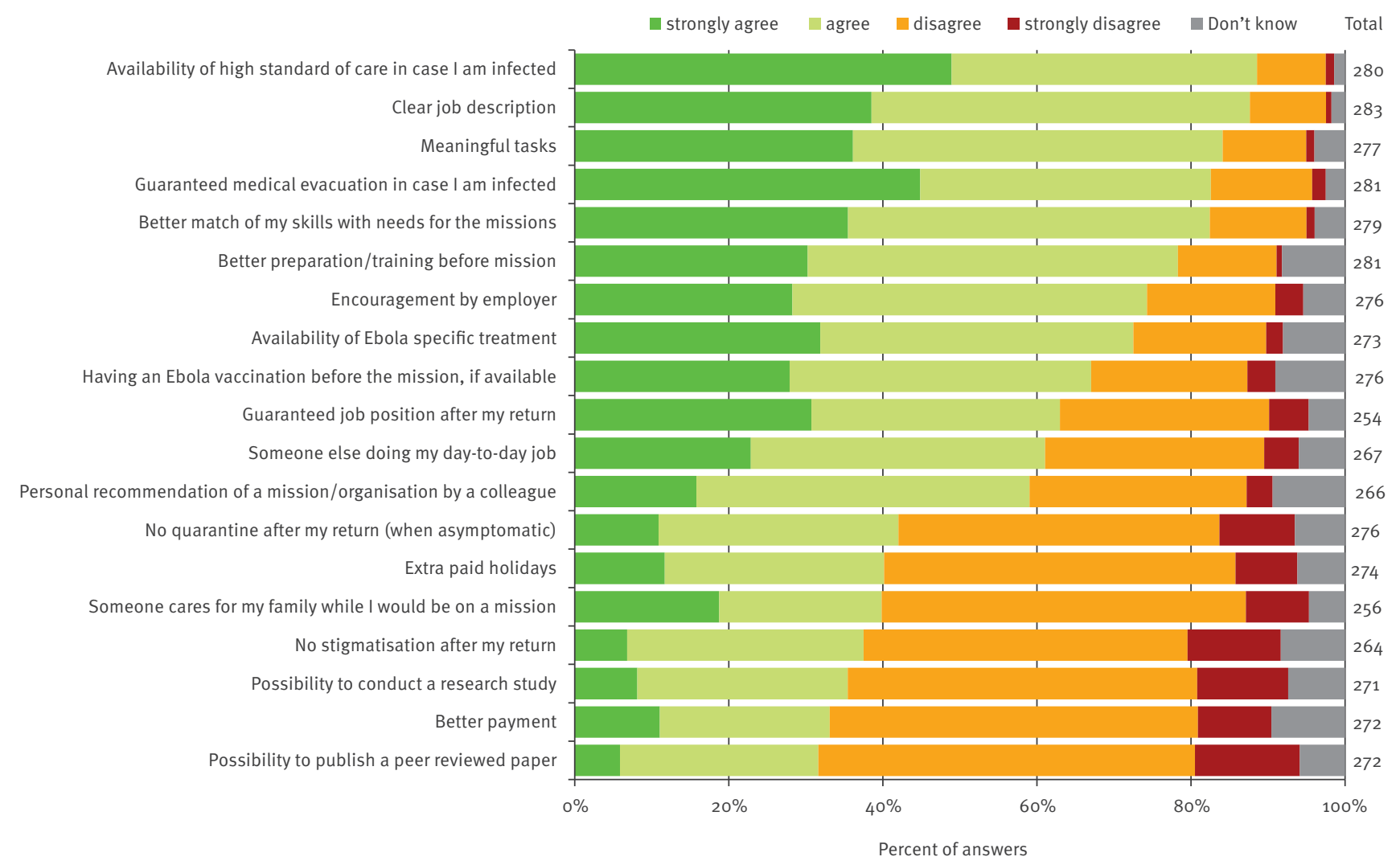

(90\%; 37/41 vs 54\%; 122/225; p<0.001). Applicants also had more confidence in their knowledge on Ebola ( $91 \% ; 42 / 46$ vs $69 \% ; 170 / 248, p=0.002)$, considered themselves as sufficiently qualified (90\%; $43 / 48$ vs $68 \% ; 158 / 232, \mathrm{p}=0.003)$ and knew how to protect themselves from Ebola ( $94 \% ; 45 / 48$ vs $72 \% ; 182 / 252$, $p=0.001)$.

\section{Comparison between experts who agree and} those who disagree with statements

The table displays the frequency of applications depending on the views and attitudes of respondents (Table).

Nobody applied to an Ebola response mission if not generally interested in such missions, physically fit or convinced to be of help. The proportion of applicants was highest among those who were directly asked to join a mission, had the time to go and had previous socio-cultural experience in West Africa (28\%; 22/80 each). Few applicants were found among respondents who were worried about an Ebola infection ( $8 \%$; 10/136) or considered a mission to West Africa as very dangerous $(5 \% ; 5 / 108)$.

\section{Experts who had returned from missions}

Among the 18 respondents, who had already completed their deployment by the time of the survey, no one regarded a mission to West Africa currently as very dangerous. However, compared with the applicants who were still ahead of their deployment $(n=26)$, they were less often convinced that reading the terms of references of a mission revealed the associated risks (8/12 vs $17 / 18)$. They agreed more often that medical evacuation was not guaranteed ( $7 / 12$ vs $6 / 15$ ), that risks were not covered well enough by sending organisations ( $5 / 12$ vs $4 / 12)$, and that the preparation and trainings for such a mission were insufficient (5/12 vs 3/17). In general, they were more concerned about infections with other diseases than Ebola virus disease (7/15 vs $8 / 25$ ). None of these differences were significant.

\section{Discussion}

International efforts to support the local response to the Ebola outbreak in West Africa encounter various difficulties and there may be questions regarding the mandate of deploying organisations, international treaties, and bilateral agreements. However, even if these were resolved, a considerable number of volunteering experts would be needed for a concerted and sustained response. Moreover, the individual decision to go or not to go on an Ebola response mission to West Africa will of course depend on careful personal considerations. 
Frequency of applications to Ebola response mission among respondents agreeing or not with various statements, European experts, December 2014

\begin{tabular}{|c|c|c|c|c|c|c|c|}
\hline \multirow{3}{*}{ Statement $^{\mathrm{a}}$} & \multicolumn{4}{|c|}{ Frequency of applications } & \multirow{3}{*}{$\begin{array}{c}\text { Prevalence } \\
\text { Ratio }^{\mathrm{b}}\end{array}$} & \multirow{3}{*}[95\%\mathrm{Cl}]{} & \multirow{3}{*}{$P$ value } \\
\hline & \multirow{2}{*}{\multicolumn{2}{|c|}{$\begin{array}{c}\text { Among agreeing } \\
\text { respondents } \\
\%(n / N)\end{array}$}} & \multirow{2}{*}{\multicolumn{2}{|c|}{$\begin{array}{c}\text { Among } \\
\text { disagreeing } \\
\text { respondents } \\
\%(n / N)\end{array}$}} & & & \\
\hline & & & & & & & \\
\hline I am generally interested in missions & 18 & $(45 / 244)$ & 0 & $(0 / 55)$ & NA & NA & 0.001 \\
\hline I think I can be of help & 20 & $(48 / 240)$ & 0 & $(0 / 49)$ & NA & NA & 0.001 \\
\hline I feel physically fit for such a mission & 18 & $(45 / 244)$ & 0 & $(0 / 44)$ & NA & NA & 0.002 \\
\hline I feel psychologically fit for such a mission & 19 & $(42 / 226)$ & 2 & $(1 / 46)$ & 8.55 & $1.21-60.55$ & 0.005 \\
\hline I have the required vaccinations & 23 & (37/159) & 4 & $(4 / 107)$ & 6.22 & $2.29-16.96$ & $<0.001$ \\
\hline I know how to protect myself from Ebola infection & 20 & $(45 / 227)$ & 4 & $(3 / 73)$ & 4.82 & $1.54-15.06$ & 0.001 \\
\hline I know enough about Ebola & 20 & $(42 / 212)$ & 4 & $(4 / 82)$ & 4.06 & $1.50-10.97$ & 0.002 \\
\hline I was asked to join field mission in the current Ebola outbreak & 28 & $(22 / 80)$ & 8 & $(16 / 208)$ & 3.58 & $1.98-6.45$ & $<0.001$ \\
\hline I have the time to go & 28 & $(22 / 80)$ & 8 & $(15 / 195)$ & 3.58 & $1.96-6.53$ & $<0.001$ \\
\hline I think I am qualified & 21 & $(43 / 201)$ & 6 & $(5 / 79)$ & 3.38 & $1.39-8.22$ & 0.003 \\
\hline I have socio-cultural experience in Western African countries & 28 & $(27 / 96)$ & 9 & $(19 / 218)$ & 3.23 & $1.89-5.51$ & $<0.001$ \\
\hline My boss would release me from my tasks & 21 & $(30 / 145)$ & 11 & $(11 / 104)$ & 1.96 & $1.03-3.72$ & 0.034 \\
\hline I am concerned about my well-being & 11 & $(20 / 185)$ & 23 & $(24 / 106)$ & 0.48 & $0.28-0.82$ & 0.007 \\
\hline I am worried I could infect others after my return & 8 & $(7 / 84)$ & 18 & $(37 / 207)$ & 0.47 & $0.22-1.00$ & 0.040 \\
\hline I am indispensable for my family & 8 & $(12 / 152)$ & 21 & $(28 / 132)$ & 0.37 & $0.20-0.70$ & 0.001 \\
\hline I am worried about getting infected with Ebola & 7 & $(10 / 136)$ & 22 & $(34 / 152)$ & 0.33 & $0.17-0.64$ & $<0.001$ \\
\hline I consider a mission to West Africa as very dangerous at the moment & 5 & $(5 / 108)$ & 22 & $(39 / 175)$ & 0.21 & $0.08-0.51$ & $<0.001$ \\
\hline
\end{tabular}

$\mathrm{Cl}$ : confidence interval; NA: not applicable.

a Only statements with significant differences are shown.

b Prevalence ratios are the proportions of applicants in agreeing over proportions of applicants in disagreeing respondents.

Our study may be limited by the convenience sampling, the possibility of information bias - i.e. respondents may have changed their decision and applied afterwards or withdrawn their application, which would result in misclassification - and the influence of social desirability bias. Nevertheless, it clearly showed that many European public health professionals felt sufficiently qualified and were willing to support the Ebola outbreak response in West Africa. Criteria that pertained to most respondents, including all those who applied for a response mission, were general interest in participating in such missions, thinking to be of help and physical fitness. Some respondents had applied for Ebola outbreak response missions despite concerns about their well-being, lack of support by their families, having small children and not having previous experience in international outbreak response missions. FETP training, international experience and confidence in own qualifications encouraged application, indicating the importance of investing into applied epidemiology and public health microbiology trainings.

A variety of obstacles hindered individual engagement though, including family constraints, uncertainty about the involved risks and work-related obstacles. Recently published articles on obstacles for volunteering health care workers in the United States and the United Kingdom also reported a lack of employers' support [8-10].

The engagement of more than 150 respondents in Ebola-related activities at the time of the survey indicated intensive resource investments of non-affected countries in their own Ebola preparedness efforts. The focus on improving own preparedness in non-affected countries is understandable. However, it might be worth reviewing how this impacts the availability of international experts for the support of affected countries.

Although stigmatisation after return, uncertainties regarding insurance coverage and medical evacuation were not considered to be a major concern, the number of applications for Ebola response missions might increase if deploying organisations took these issues into account in the planning of missions. Our survey showed that clear job descriptions, meaningful tasks, and improved preparation and training efforts would enhance the willingness of experts to apply for Ebola response missions. These understandable and realistic expectations towards the deploying organisations were also supported by the views of returning experts. 
Finally, European public health organisations, deploying organisations and policy makers should further improve the required general conditions to enable the deployment of experts to international missions. This includes sustained investment in developing competencies and broadening international experience of experts e.g. through FETPs, and encouraging employers to support their employees if they volunteer for missions. These efforts should strengthen the response to the present Ebola outbreak, as well as improve and secure international response to future crises.

\section{Acknowledgments}

The authors thank all respondents for their time and openness, Florian Burckhardt and Yvan Hutin for their valuable input and the EAN board for the support in distributing the questionnaire.

\section{Conflict of interest}

None declared.

Authors' contributions

UR and MD drafted the questionnaire, conducted the analysis, wrote the manuscript; EP, CW, MadH and AG contributed to the questionnaire and revised the draft manuscript.

\section{References}

1. World Health Organization (WHO). Ebola Situation reports. Geneva: WHO. [Accessed 27 February 2015]. Available from: http://www.who.int/csr/disease/ebola/situation-reports/en/

2. Ebola: time to act. Nature. 2014;513(7517):143-4. http://dx.doi. org/10.1038/513143b PMID:25209760

3. Tambo E, Ugwu EC, Ngogang JY. Need of surveillance response systems to combat Ebola outbreaks and other emerging infectious diseases in African countries. Infect Dis Poverty. 2014;3:29. doi: 10.1186/2049-9957-3-29. eCollection 2014 .

4. Gulland A. More health staff are needed to contain Ebola outbreak, warns WHO. BMJ. 2014;349(sepo4 8):g5485. http:// dx.doi.org/10.1136/bmj.g5485 PMID:25193934

5. Krause G, Aavitsland P, Alpers K, Barrasa A, Bremer V, Helynck $B$, Perra A. Differences and commonalities of national field epidemiology training programmes in Europe. Euro Surveill. 2009;14(43). PMID:19883560

6. Pezzoli L, Keramarou M, Ladbury G, Jaramillo-Gutierrez G, Williams CJ, LE Menach A. Time, place, and people: composition of the EPIET Alumni Network and its contribution to the European public health resource in 2013. Epidemiol Infect. 2014;1-8. http://dx.doi.org/10.1017/ So950268814003392 PMID:25521307

7. LimeSurvey Project Team / Carsten Schmitz. (2012). / LimeSurvey: An Open Source survey tool /LimeSurvey Project Hamburg, Germany. Available from: http://www.limesurvey.org

8. Rosenbaum L. License to serve--U.S. trainees and the Ebola epidemic. N Engl J Med. 2015;372(6):504-6. http://dx.doi. org/10.1056/NEJMp1415192 PMID:25517575

9. Mello MM, Merritt MW, Halpern SD. Supporting those who go to fight ebola. PLoS Med. 2015;12(1):e1001781. http://dx.doi. org/10.1371/journal.pmed.1001781 PMID:25622033

10. Turtle L, McGill F, Bettridge J, Matata C, Christley R, Solomon T. A Survey of UK Healthcare Workers' Attitudes on Volunteering to Help with the Ebola Outbreak in West Africa. PLoS ONE 2015;10(3):e0120013. http://dx.doi.org/10.1371/journal. pone.0120013 PMID:25760763 